\title{
Statistical analysis and optimum performance of the gas turbine power plant
}

\author{
Thamir K. Ibrahim ${ }^{1,2 *}$, M.M. Rahman ${ }^{1,}$ M.K. Mohammed ${ }^{3}$ and Firdaus Basrawi $^{1}$ \\ ${ }^{1}$ Faculty of Mechanical Engineering, Universiti Malaysia Pahang, \\ 26600 Pekan, Pahang, Malaysia. \\ Email: thamirmathcad@yahoo.com; thamir@ump.edu.my; \\ ${ }^{2}$ Mechanical Engineering Departments, \\ College of Engineering, University of Tikrit, Iraq \\ ${ }^{3}$ Mechanical Engineering Department, University of Sharjah, UAE.
}

\begin{abstract}
The statistical analyses of the gas turbine power plant are presented in this paper. A novel approach for analysing gas turbine operation and performance is developed utilizing statistical modelling technology, specifically response surface methodology (RSM) which was based on the central composite design (CCD) applied. The proposed correlations have a remarkably satisfactory performance for all simulation data, where the determination coefficient $\left(R^{2}\right)$ about 0.985 . Moreover, the newly developed correlations were validated with the real data from the gas turbine of MARAFIQ CCGT power plant. Moreover, the newly developed correlations were validated with the real data from the GT units in the MARAFIQ CCGT power plant. The error analysis was applying to approximation the error (1.123\% of the GT plants). From applied the ANFIS technique, the optimum thermal efficiency was about $56 \%$ with the effect of the pressure ratio and compressor isentropic efficiency.
\end{abstract}

Keywords: Gas-turbine, ambient temperature, pressure ratio, statistical analyses, optimization.

\section{INTRODUCTION}

The high performance of plant can be judged by its power generation, fuel consumption, working ratio and the thermal efficiency [1-4]. It is reported that various aspects are there which greatly influence the performance which is: surrounding temperature, pressure ratio, combustion and the turbine inlet temperatures, etc. [5-9]. According to Taniguchi et al., [10], the performance of GT plant is very much affected by the ambient temperature and pressure along with the temperature recorded of wear out gases. The study shows that a clear decline in power generation of about $10 \%$ is observed as the ambient temperature increases, whenever the ambient air temperature increases to $30{ }^{\circ} \mathrm{C}$ from ISO stated condition of $\left(15^{\circ} \mathrm{C}\right)$. This situation is very much common in the tropical climatic region where the recorded temperature varies from $25^{\circ} \mathrm{C}$ to $35^{\circ} \mathrm{C}$ [11-14]. The favourable conditions for increasing the working capacity of a CCGT power generation plant are: the intake temperature of is decreased to $15^{\circ} \mathrm{C}$ (ISO) and the humidity (RH) are maintained to about $100 \%$ before the entrance in GT power plant compressor. These conditions of GT power plant are commonly measured to check the efficiency and power generation capacity of the plant [15-18]. The operating limits mentioned above like pressure ratio, ambient temperature, air-fuel ratio, turbine inlet temperature, compressor as well as 
turbine isentropic efficiency is continuously applied to the performance of GT plant [19, 20]. However these are not forever positively activated in the turbine, these parameters should be properly controlled so that performance of gas turbine can be maintained accordingly. An efficient and accurate study must be carried out so as to maintain the parameters along with the working and capacity of the plant [21-23]. As per the required ISO conditions affecting the performance of GT power plant, a proper strategy must be followed to achieve the maximum output. Badran [24] carried out a parametric study to investigate the effect of different parameters (turbine inlet temperatures, pressure, combustion efficiency, and isentropic compressor and turbine efficiency) on the performance of the GT plant. The calculation of the values of the performance parameters was using equations of the basic cycle with assuming thermodynamic properties at constant values. Arrieta and Lora [25] evaluated the impact of ambient temperature on the performance of the CCGT plant. Furthermore, during the design stage, the influence of the ambient temperature on the performance of the CCGT plant to be considered. The heating temperature of the fuel gas results in a higher thermal efficiency of the GT due to the reduced fuel consumption [23, 26, 27]. Thamir and Rahman [8] examined thermodynamic analysis of the GT system. The effect of the parameters such as pressure ratio, turbine inlet temperature and isentropic compressor and turbine efficiency in the GT performance was modelled and analysed. The thermal efficiency and power output is selected as an indicator for measured the system performance. Maximum cycle temperature selected depends on the ability of the material that used in the gas-turbine plant at full load and ISO conditions [18]. The response of the GT performance to the various operation parameters shall form the initial stage of the investigation, followed by a tracking for the optimum parameters. Thus, the aim of the present work is to develop new predictive correlations for the performance of the GT power plants.

\section{STATISTICAL ASSESSMENT AND OPTIMIZATION TECHNIQUES}

The reliability of the physical systems simulation is largely dependent on the mathematical model's accuracy. To be able to carry quantitative modelling of any component, mathematical knowledge is very crucial and one should have the efficient level [28]. The process was not represented meaningfully by the mathematical model when it was used instead of the equipment itself. Hence, for authentication that the mathematical model is a true representation of the actual plant, readings from the actual plant must be taken which prove or elucidate this fact [29]. Additionally, statistical analysis is also carried out taking the errors into account of both the modelled data and the actual readings of the plant to examine the variations present. The basic energy and mass balance equations have been used by some researchers, while the commercial software for modelling and analysis has been utilized by others in developing the performance of the GT. The structure models shape up the problem by deviating from normal conditions that are often associated with approximations of experimental relationships, linearization and real processes [30, 31]. Moreover, for modelling GT cycle, traditional models generally incorporate a multitude of parameters. Soft computing, which solves complex mathematical problems is one of the realistic choices for overcoming these problems. In identifying problems and solving complex systems, the major components of soft computing, fuzzy logic and neural networks have been classified as being capable enough [32]. The core concept of artificial intelligence is represented by these methods, applicable in various fields relating to computational studies. Based on the Adaptive Neuro-fuzzy inference system (ANFIS) as a hybrid 
technique, an optimization model of the performance of GT in this study was developed. For studying the heat rate and performance of a power plant, the hybrid artificial neural network (ANN) approach with three-layer was proposed. Figure 1 shows two-input firstorder Sugeno fuzzy model with two rules and equivalent ANFIS architecture. As a function the system is equivalent to a first-order Sugeno fuzzy inference system whereas it is also an adaptive network [33]. A rule combining back-propagation and a least-squares algorithm is used for identifying and optimizing the parameters of the Sugeno system while the hybrid learning utilizes ANFIS. Under contemplation, the fuzzy inference system assumed has two inputs $(x)$ and $(y)$ namely and one output $(f)$. Hence, as the following confirms, a regular set of two fuzzy if-then rules is taken for a first-order Sugeno model $[34,35]$. To estimate the output with key parameters, ANFIS is used to develop a GT model in this study. The thermal efficiency power output and fuel consumption are estimated effectively by using this ANFIS based GT cycle model.

Rule 1: If $x$ is $\mathrm{A} 1$ and $y$ is $\mathrm{B} 1$, then $f_{1}=p_{1} x+q_{1} y+r_{1}$

Rule 2: If $x$ is $\mathrm{A} 2$ and $y$ is $\mathrm{B} 2$, then $f_{2}=p_{2} x+q_{2} y+r_{2}$

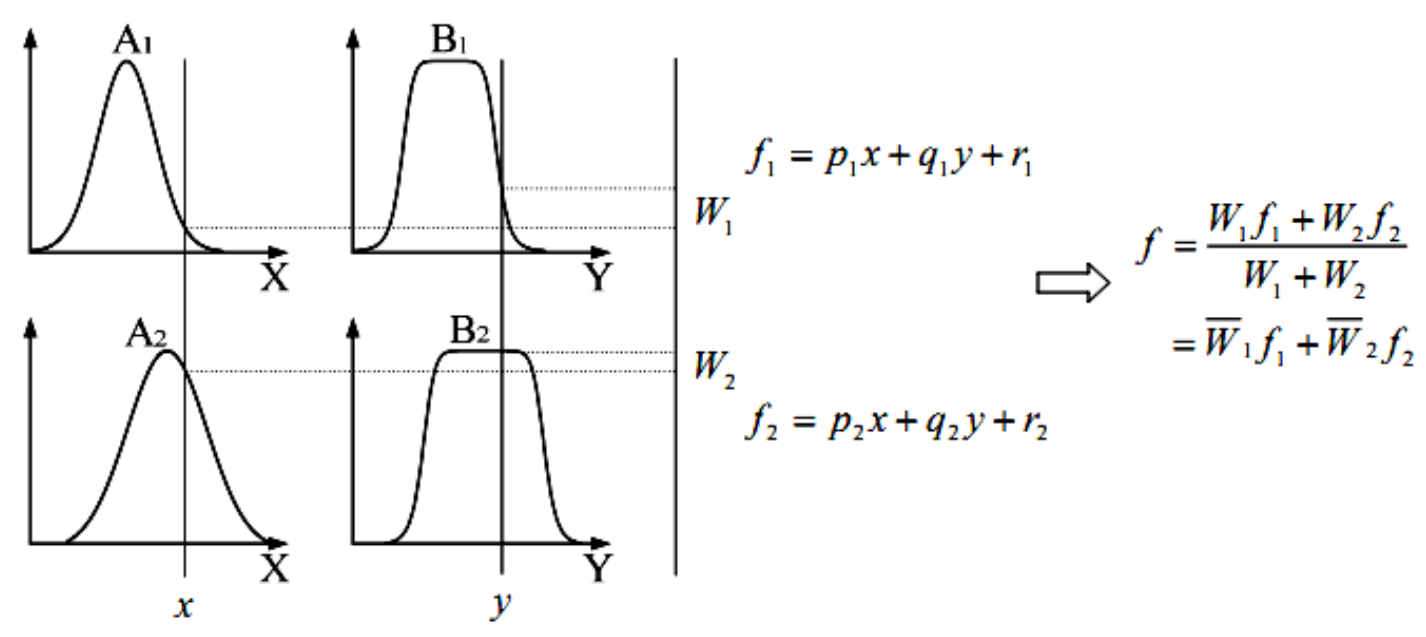

(a)

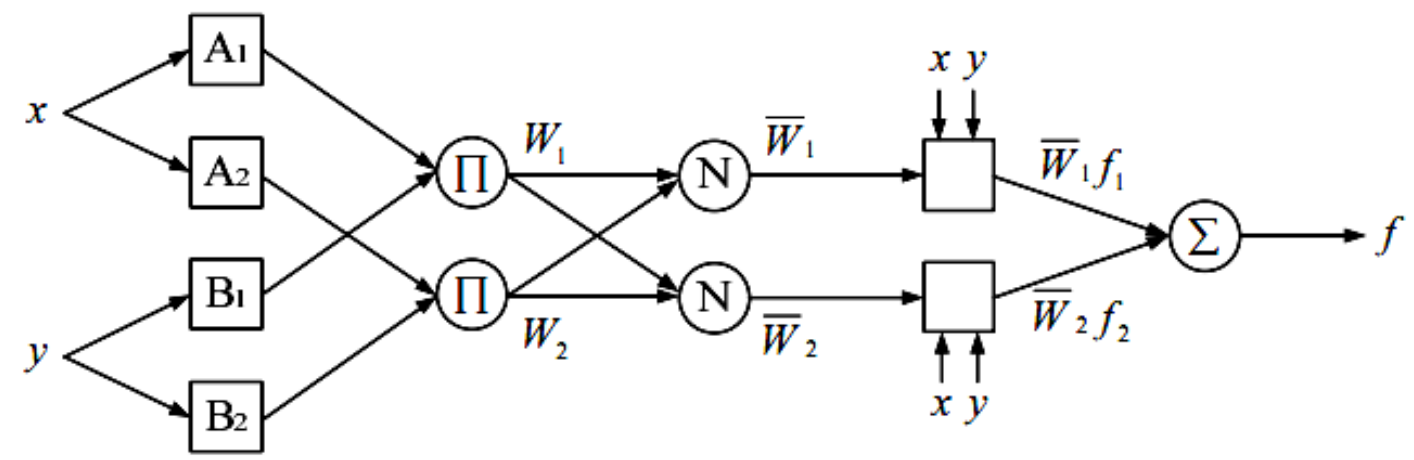

Layer 1 Layer 2 Layer $3 \quad$ Layer $4 \quad$ Layer 5

(b)

Figure 1. (a) Two-input first-order Sugeno fuzzy model with two rules. (b) Equivalent ANFIS architecture. 
Prediction of the GT power plant outputs was done by developing input-output relationships through this study. Moreover, a phased strategy was envisioned so that the effects of variables and its counterparts can be realized. Furthermore, a model was created that could predict from real data power outputs of the GT power plants. For this, RSM, also known as response surface methodology which was based on the CCD, also known as the central composite design was applied. Moreover, transfer functions can also be predicted based on this RSM technique. This study utilizes the CCD technique, as stated by Montgomery, [36] and $\mathrm{Wu}$ and Hamad, [37]. Estimation of systems or processes behaviour is done by using DOE (design of experiment) technique based on statistics. As a case study, the GT unit in the the MRAFAQ CCGT plant is chosen. Table 1 shows the ANOVA results which highlight the variance analysis. The model is indeed noteworthy as highlighted by the model F-value of 183.80 shown. The possibility of such a huge value of the Model-F occurring due to the presence of noise is only $0.01 \%$. Moreover, the value of 'Prob $>F$ ' that are less than 0.0500 highlights the worth of these model terms, as shown in this scenario like $r_{p}^{2}, T_{1}^{2}, T_{1}$ and $T_{1} * r_{p}$. On the other hand, values which are greater than 0.100 holds are insignificant. Based on the response surface technique, the GTs power plant mathematical model has been developing. Equation (1) illustrates how the GTs plant power output can be evaluated.

Table 1. Analysis of the GTs plant variance (ANOVA) results.

\begin{tabular}{|c|c|c|c|c|c|}
\hline Source & $\begin{array}{l}\text { Sum of } \\
\text { Squares }\end{array}$ & $\mathrm{df}$ & $\begin{array}{l}\text { Mean } \\
\text { Square }\end{array}$ & $\begin{array}{l}\text { F } \\
\text { Value }\end{array}$ & $\begin{array}{l}\text { p-value } \\
\text { Prob > F }\end{array}$ \\
\hline Model & 9725.662 & 5 & 1945.132 & 183.8 & significant \\
\hline $\mathrm{A}\left(\mathrm{T}_{1}\right)$ & 127.7475 & 1 & 127.7475 & 12.07115 & 0.0031 \\
\hline $\mathrm{B}\left(\mathrm{r}_{\mathrm{p}}\right)$ & 25.39606 & 1 & 25.39606 & 2.399731 & 0.1409 \\
\hline $\mathrm{AB}$ & 58.36003 & 1 & 58.36003 & 5.514572 & 0.0320 \\
\hline $\mathrm{A}^{\wedge} 2$ & 47.94655 & 1 & 47.94655 & 4.530578 & 0.0492 \\
\hline $\mathrm{B}^{\wedge} 2$ & 93.99703 & 1 & 93.99703 & 8.881992 & 0.0088 \\
\hline Residual & 169.326 & 16 & 10.58288 & & \\
\hline $\begin{array}{l}\text { Cor } \\
\text { Total }\end{array}$ & 9894.988 & 21 & & & \\
\hline
\end{tabular}

$$
\begin{aligned}
\text { power of } \mathrm{GT} & =+22129.84398-54.16951 T_{1}-1792.53165 r_{p} \\
& +2.21464 T_{1} r_{p}+0.032553 T_{1}^{2}+38.21063 r_{p}^{2}
\end{aligned}
$$

where, Power of GT represents the gas turbines output power (MW) $r_{p}$ is the gas turbines cycle pressure ratio and $T_{1}$ is the ambient temperature $(\mathrm{K})$

Table 2. $R^{2}$ analysis results of the GT plant.

\begin{tabular}{llll}
\hline Parameter & Value & Parameter & Value \\
\hline Std. Dev. & 3.25 & R-Squared & 0.9829 \\
Mean & 492.2 & Adj R-Squared & 0.9775 \\
C.V.\% & 0.66 & Pred R-Squared & 0.9548 \\
PRESS & 447.16 & Adeq Precision & 39.002 \\
\hline
\end{tabular}




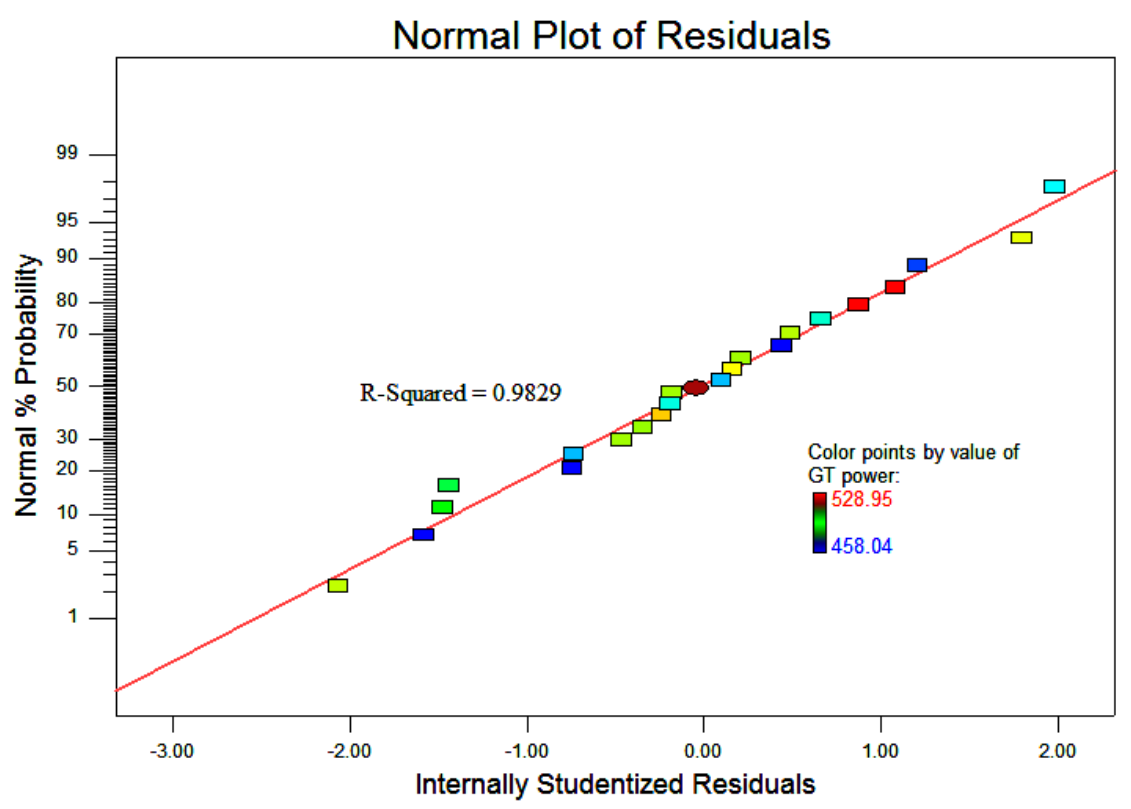

Figure 2. Normal probability plot of residuals

Table 3. Comparison between real data of the GT plant versus predicted results by DOE

\begin{tabular}{lllllll}
\hline Run & $\mathrm{r}_{\mathrm{p}}$ & $\begin{array}{l}\mathrm{T}_{1} \\
(\mathrm{~K})\end{array}$ & $\begin{array}{l}\text { Actual Power } \\
(\mathrm{MW})\end{array}$ & $\begin{array}{l}\text { Predicted Power by } \\
\text { DOE }(\mathrm{MW})\end{array}$ & Residuals & \% Deviation \\
\hline 1 & 15.64 & 291.34 & 508 & 513.9439 & -5.9439 & -1.17006 \\
2 & 15.55 & 293.97 & 506.69 & 508.1174 & -1.4274 & -0.28171 \\
3 & 15.54 & 294.43 & 506.22 & 507.4515 & -1.2315 & -0.24327 \\
4 & 15.55 & 295.38 & 506.7 & 507.4775 & -0.7775 & -0.15344 \\
5 & 15.54 & 296.84 & 507.55 & 506.4844 & 1.0656 & 0.20995 \\
6 & 15.68 & 293.97 & 514.06 & 514.5836 & -0.5236 & -0.10186 \\
7 & 15.85 & 298.31 & 528.95 & 526.6646 & 2.2854 & 0.432064 \\
8 & 15.79 & 299.03 & 524.29 & 521.8558 & 2.4342 & 0.464285 \\
9 & 15.26 & 317.42 & 484.48 & 487.2425 & -2.7625 & -0.5702 \\
10 & 14.87 & 315.1 & 467.14 & 464.2049 & 2.9351 & 0.628313 \\
11 & 15.34 & 308.41 & 487.19 & 491.1739 & -3.9839 & -0.81773 \\
12 & 14.78 & 310.19 & 463.73 & 465.833 & -2.103 & -0.4535 \\
13 & 14.99 & 307.95 & 472.3 & 474.5655 & -2.2655 & -0.47967 \\
14 & 15.1 & 308.76 & 477.73 & 478.4206 & -0.6906 & -0.14456 \\
15 & 14.74 & 314.2 & 461.35 & 460.1001 & 1.2499 & 0.270922 \\
16 & 14.65 & 311.36 & 458.04 & 461.6352 & -3.5952 & -0.78491 \\
17 & 14.97 & 309.83 & 472.41 & 472.0958 & 0.3142 & 0.06651 \\
18 & 14.99 & 305.71 & 478.58 & 476.7298 & 1.8502 & 0.386602 \\
19 & 14.96 & 311.85 & 476.1 & 470.1357 & 5.9643 & 1.252741 \\
20 & 15.39 & 290.7 & 509.63 & 505.0036 & 4.6264 & 0.907796 \\
21 & 15.46 & 287.83 & 510.56 & 510.2262 & 0.3338 & 0.065379 \\
\hline
\end{tabular}

$\%$ of deviation $=[($ actual value - predicted value $) /$ actual value $] \times 100 \%$ 


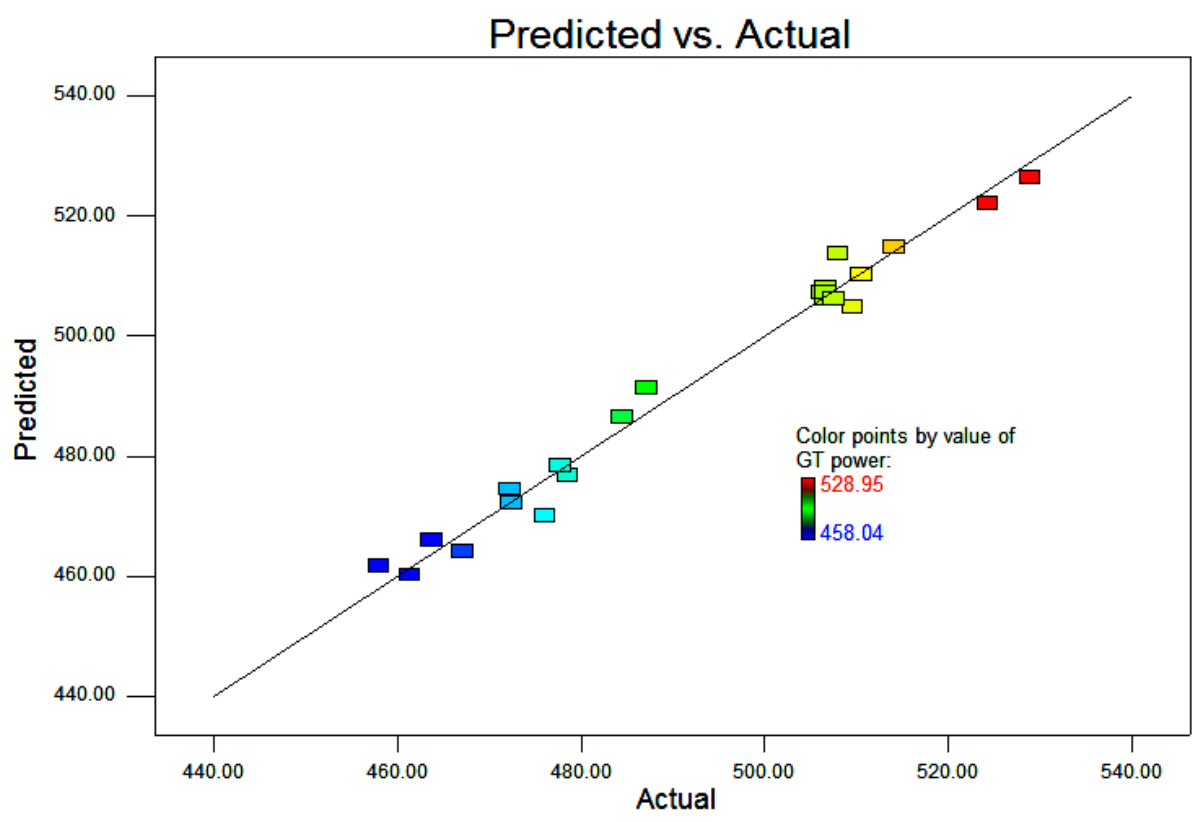

Figure 3. GT power outputs best-fit line.

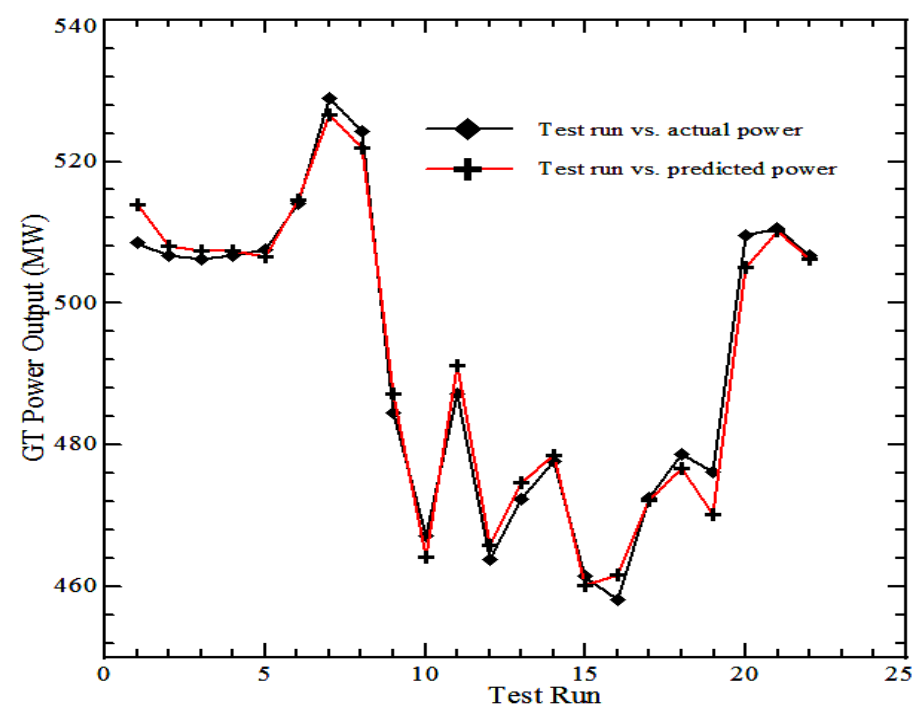

Figure 4. The contrast between predicted results versus real data of the GT.

In Table 2 lists down $\mathrm{R}^{2}$ evaluation results of the GT plant which is used to measure the power output of the plant. As shown in Table 2, the adjusted R-squared value of 0.9775 and the Predict R-squared value of 0.9548 are in close proximity to each other. The signal to noise ratio is calculated by the parameter named adequate precision. Here a value greater than 4 is appropriate. More so, if the ratio is 39.002 , that indicates that the signal is acceptable. Furthermore, a value of $\mathrm{R}^{2}$ on a higher side indicates that the results are close to the real data values. A comparison between the actual data and the predicted one is highlighted in Table 3. A set of data based on 21 trials were collected as per the CCD structure and a table was constructed which incorporated the predicted responses from RSM too. The values seem to coincide with the actual data which is considered good. It also shows the residual by response surface and the percentage variation versus the run number. More so, coverage against trends as well as autocorrelation is provided by the help of randomization. A normal plot of residuals is shown in Figure 2. The graphs highlight one key fact, that is, the value of $R^{2}=0.9829$ 
shows no irregularity. The linear model is statistically adequate and can be used to steer the design space. Figure 3 shows a plot of the predicted values versus the actual data set whereas the graphical representation is shown in Figure 4. It can be seen that the best-fit line resembles the $(\mathrm{Y}=\mathrm{X})$ line when plotted on a data set of 21 points. This indicates that the predicted values and the real data are in close proximity to each other. Moreover, the bowling score can also be anticipated more accurately from the scattered points on the plot. The variation found in actual results from the predicted ones were between 5.9643 and -5.9439 showing only a small dissimilarity, whereas a value of -0.07747 was the case for the average absolute residuals. It was due to cyclic variations that accounted for this minor difference between the real and the predicted data.

\section{Uncertainty Analysis}

A detailed systematic error analysis (Uncertainty analysis) is carried out to approximation the errors related to the experimental analysis of the power output of the GT power plant [38]. The uncertainties in the values estimated with different instruments are given in Tables 4 for GT. The maximum possible errors for the parameters involved in the analysis are in Table 5. The analysis of the uncertainty of the GT was expressed as in Eq. (2):

$$
\frac{U_{P_{G T}}}{P_{G T}}=\sqrt{\left(\frac{\delta P}{\delta T_{1}}\right)^{2} * w_{T_{1}}^{2}+\left(\frac{\delta P}{\delta r_{p}}\right)^{2} * w_{r_{p}}^{2}}
$$

where, $\mathrm{W}_{\mathrm{T} 1}=$ Temperature least division; $\mathrm{W}_{\mathrm{rp}}=$ Pressure ratio least division

Table 4. Uncertainties of a parameter of the GT.

\begin{tabular}{lll}
\hline Calibration parameter & Unit & Uncertainty error (\%) \\
\hline Power output of the GT & MW & 1.123 \\
\hline
\end{tabular}

Table 5. Uncertainties of instruments and properties.

\begin{tabular}{|c|c|c|c|c|c|c|}
\hline $\begin{array}{l}\text { Item } \\
\text { No. }\end{array}$ & $\begin{array}{l}\text { Name of } \\
\text { instrument }\end{array}$ & $\begin{array}{l}\text { Range of } \\
\text { instrument }\end{array}$ & $\begin{array}{l}\text { Variable } \\
\text { measured }\end{array}$ & $\begin{array}{l}\text { Least } \\
\text { division in } \\
\text { measuring } \\
\text { instrument }\end{array}$ & $\begin{array}{l}\text { Min. and } \\
\text { max. values } \\
\text { measured in } \\
\text { experiment }\end{array}$ & $\begin{array}{l}\text { Uncertainty } \\
\text { error }(\%)\end{array}$ \\
\hline 1 & Thermocouple & $0-120{ }^{\circ} \mathrm{C}$ & $\begin{array}{l}\text { Ambient } \\
\text { Temperature }\end{array}$ & $0.2{ }^{0} \mathrm{C}$ & $\begin{array}{l}14.44-44.9 \\
{ }^{0} \mathrm{C}\end{array}$ & 0.0991 \\
\hline 2 & Pressure Gage & 0-20 bar & $\begin{array}{l}\text { Compressed } \\
\text { Air Pressure }\end{array}$ & 0.1 bar & $\begin{array}{l}14.6-15.96 \\
\text { bar }\end{array}$ & 0.6544 \\
\hline
\end{tabular}

\section{Optimization Techniques}

The power output, the thermal efficiency and the specific fuel consumption were considered as the performance parameters. The effects of many parameters, such as the pressure ratio, ambient temperature, turbine inlet temperature, and isentropic compressor and turbine efficiency on the performance parameters of GT plants were discussed. However, adaptive Neuro-fuzzy inference system (ANFIS) used to select optimum parameters, which give the peak performance. Consequently, it is important to represent the effect of the optimum parameters on the plant performance. The effect of the optimum parameters on the performance of GT cycles was presented. The trends of the performance of the simple GT (SGT) cycle with the effect of the optimum parameters are 
shown in Figure 5. Figure 5(a) presents the optimum thermal efficiency with the effect of the pressure ratio and compressor isentropic efficiency. From applied the ANFIS technique, the optimum thermal efficiency occurred with the increase of the pressure ratio and isentropic compressor efficiency. This is because of the thermal efficiency function of the pressure ratio. Also, the increased isentropic compressor efficiency caused decreased of the losses then increased the thermal efficiency [6, 39]. It was obtained the peak value about $56 \%$ when the pressure ratio and isentropic compressor efficiency 30 and $100 \%$ respectively. Furthermore, the lower thermal efficiency was about 10\%, when the pressure ratio and isentropic compressor efficiency 30 and $70 \%$ respectively. This behaviour is well agreed with the previous observation reported by Kurt et al. [40].

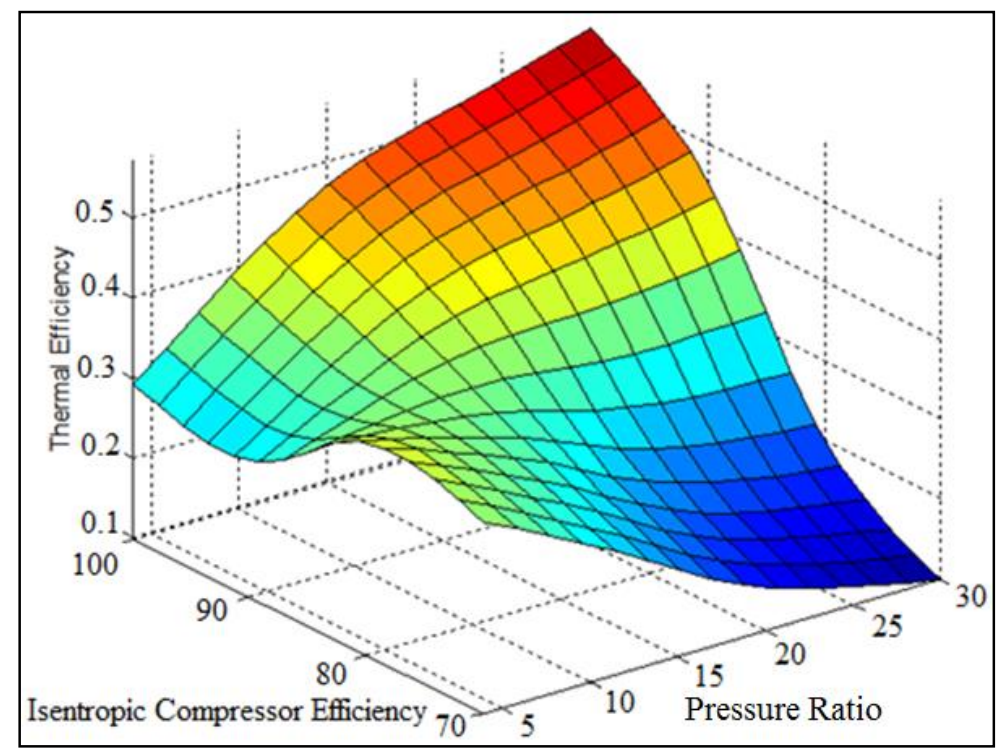

(a) Thermal efficiency

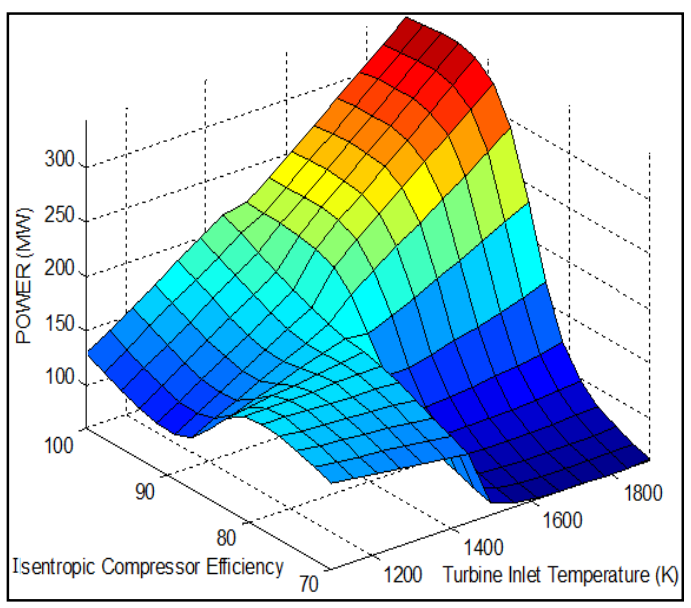

(b) Power

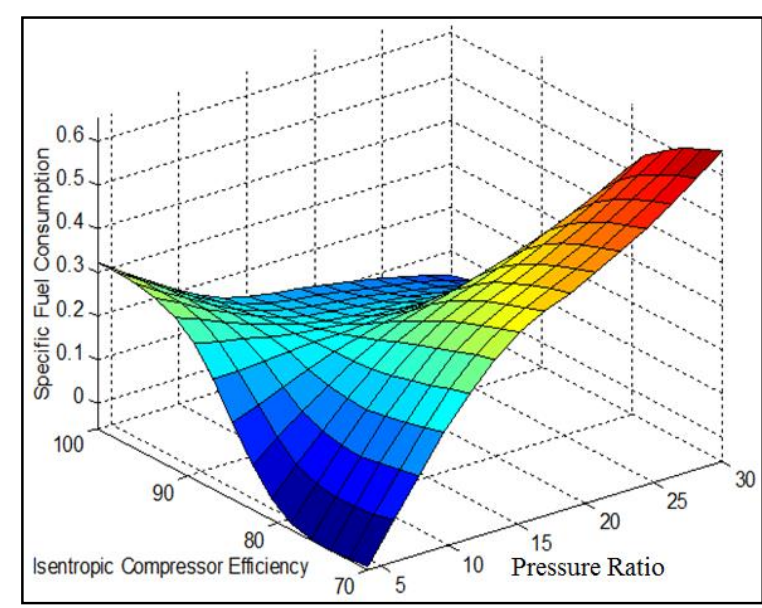

(c) Specific fuel consumption

Figure 5. SGT performance trends with peak parameters.

Figure 5(b) shows the variation of the optimum power output with the effect of the turbine inlet temperature and isentropic compressor efficiency. Clearly, the power output increases with increases in the turbine inlet temperature. This is because of the 
increase the work done by the turbine of the GT plant [6, 22, 41]. Furthermore, when the isentropic compressor efficiency increases the power output increases due to decreases the consumption power, which required driving the compressor $[9,11,17,25]$. It can also be seen that the maximum power output was about 370MW, when the turbine inlet temperature and isentropic compressor efficiency $1900 \mathrm{~K}$ and $100 \%$ respectively. The minimum power output was about $100 \mathrm{MW}$, when the turbine inlet temperature and isentropic compressor efficiency $1900 \mathrm{~K}$ and $700 \%$ respectively. Figure 5(c) indicates the peak value of the fuel consumption with the effect of the pressure ratio and isentropic compressor efficiency. It is clear that, the specific fuel consumption decreased, when the pressure ratio and the isentropic compressor efficiency decreases, which gives a lower thermal efficiency. While, when the pressure ratio and the isentropic compressor efficiency increase, the specific fuel consumption increased, which gives higher thermal efficiency. This is because of the losses of the SGT reduced with increased of the isentropic compressor efficiency, thus the specific fuel consumption decreased. Therefore, the optimum value of the specific fuel consumption was about $0.05 \mathrm{~kg} / \mathrm{kWh}$, when the pressure ratio and isentropic compressor efficiency 30 and $100 \%$ respectively.

\section{CONCLUSIONS}

To improve the system of checking the performance of GT power plants and their power output new techniques of analytical correlations were launched, which were mostly evaluated statistically. This technology of correlation was considered satisfactory for all types of simulation data, whose coefficient of determination (R2) was calculated as 0.985 . Some of the latest launched correlations were checked on the real working of GT units in the MARAFIQ CCGT plant. Error analysis is also conducted to approximation error recorded as $1.123 \%$ of GT power plants. The performance of the GT was judged by particular parameters opted from the simulation model of performance and also utilized Adaptive Neuro-Fuzzy System (ANFIS) an advanced new optimization technology. For the approaches of GT, the best thermal efficiency attained was about 56\%. It was with best possible pressure ratio and the isentropic compressor efficiency.

\section{ACKNOWLEDGEMENTS}

The authors would like to be obliged to Universiti Malaysia Pahang for providing laboratory facilities and financial assistance under research grant (RDU150334).

\section{REFERENCES}

[1] Ibrahim TK, Rahman MM. Effects of Isentropic Efficiency and Enhancing Strategies on Gas Turbine Performance. Journal of Mechanical Engineering and Sciences. 2013;4:383-96.

[2] Nawi MRM, Mamat AMI, Ismail H. Numerical heat transfer analysis of waste heat exchanger for exhaust gas energy recovery. Journal of Mechanical Engineering and Sciences. 2015;8:1498-506.

[3] Ibrahim TK, Rahman MM. Effect of Compression Ratio on the Performance of Different Strategies for the Gas Turbine. International Journal of Automotive and Mechanical Engineering. 2014;9:1747-57. 
[4] Muhamad Said MF, Aroussi A. Utilization of Pulverised Coal Monitoring System for Cleaner Electricity Generation. International Journal of Automotive and Mechanical Engineering. 2014;9:1588-98.

[5] Farzaneh-Gord M, Deymi-Dashtebayaz M. A new approach for enhancing performance of a gas turbine (case study: Khangiran refinery). Applied Energy. 2009;86:2750-9.

[6] Ibrahim TK, Rahman M. Effect of the isentropic efficiency and enhancing strategies on the performance of gas turbine. Journal of Mechanical Engineering and Sciences. 2013;4:383-96.

[7] Ibrahim TK, Rahman M. Parametric study of a two-shaft gas turbine cycle model of power plant. IOP Conference Series: Materials Science and Engineering: IOP Publishing; 2012. p. 012024.

[8] Rahman M, Ibrahim TK, Abdalla AN. Thermodynamic performance analysis of gas-turbine power-plant. International Journal of Physical Sciences. 2011;6:353950 .

[9] Nada T. Performance characterization of different configurations of gas turbine engines. Propulsion and Power Research. 2014;3:121-32.

[10] Taniguchi H, Miyamae S, Arai N, Lior N. Power generation analysis for hightemperature gas turbine in thermodynamic process. Journal of Propulsion and Power. 2000;16:557-61.

[11] Ibrahim TK, Rahman M. Effect of compression ratio on performance of combined cycle gas turbine. International journal of energy engineering. 2012;2:9-14.

[12] Ibrahim TK, Rahman M. Parametric simulation of triple-pressure reheat combined cycle: A case study. Advanced Science Letters. 2012;13:263-8.

[13] Ibrahim TK. the Life Cycle Assessments of Gas Turbine using Inlet Air Cooling System. Tikrit Journal of Engineering Science (TJES). 2015;22:69-75.

[14] Han W, Chen Q, Lin R-m, Jin H-g. Assessment of off-design performance of a small-scale combined cooling and power system using an alternative operating strategy for gas turbine. Applied Energy. 2015;138:160-8.

[15] Khaliq A, Choudhary K. Thermodynamic performance assessment of an indirect intercooled reheat regenerative gas turbine cycle with inlet air cooling and evaporative after cooling of the compressor discharge. International journal of energy research. 2006;30:1295-312.

[16] Carcasci C, Costanzi F, Pacifici B. Performance Analysis in Off-design Condition of Gas Turbine Air-bottoming Combined System. Energy Procedia. 2014;45:1037-46.

[17] Ibrahim TK, Mohammed MN. Thermodynamic Evaluation of the Performance of a Combined Cycle Power Plant. International Journal of Energy Science and Engineering. 2015;1:11.

[18] Ibrahim TK, Rahman M, Ali OM, Basrawi F, Mamat R. Optimum Performance Enhancing Strategies of the Gas Turbine Based on the Effective Temperatures. MATEC Web of Conferences: EDP Sciences; 2016.

[19] Ibrahim TK, Rahman M, Alla ANA. Study on the effective parameter of gas turbine model with intercooled compression process. Scientific Research and Essays. 2010;5:3760-70.

[20] Rahman MM, Ibrahim TK, Kadirgama K, Mamat R, Bakar RA. Influence of operation conditions and ambient temperature on performance of gas turbine power plant. Advanced Materials Research: Trans Tech Publ; 2011. p. 3007-13. 
[21] Kolev N, Schaber K, Kolev D. A new type of a gas-steam turbine cycle with increased efficiency. Applied thermal engineering. 2001;21:391-405.

[22] Ibrahim TK, Rahman M. Effective Parameters on performance of multipressure combined cycle power plants. Advances in Mechanical Engineering. 2014;6:781503.

[23] Ibrahim TK, Rahman MM. Study on effective parameter of the triple-pressure reheat combined cycle performance. Therm Sci. 2013;17:497-508.

[24] Badran OO. Gas-turbine performance improvements. Applied Energy. 1999;64:263-73.

[25] Arrieta FRP, Lora EES. Influence of ambient temperature on combined-cycle power-plant performance. Applied Energy. 2005;80:261-72.

[26] Basha M, Shaahid S, Al-Hadhrami L. Impact of fuels on performance and efficiency of gas turbine power plants. Energy Procedia. 2012;14:558-65.

[27] Verstraete D, Bowkett C. Impact of heat transfer on the performance of micro gas turbines. Applied Energy. 2015;138:445-9.

[28] Lyu MR. Handbook of software reliability engineering: IEEE computer society press CA; 1996.

[29] Wohlin C, Runeson P, Höst M, Ohlsson MC, Regnell B, Wesslén A. Experimentation in software engineering: Springer Science \& Business Media; 2012.

[30] Jurado F, Ortega M, Cano A, Carpio J. Neuro-fuzzy controller for gas turbine in biomass-based electric power plant. Electric Power Systems Research. 2002;60:123-35.

[31] Chan Y-K, Gu J-C. Modeling of turbine cycles using a neuro-fuzzy based approach to predict turbine-generator output for nuclear power plants. Energies. 2012;5:101-18.

[32] Yang L, Entchev E. Performance prediction of a hybrid microgeneration system using Adaptive Neuro-Fuzzy Inference System (ANFIS) technique. Applied Energy. 2014;134:197-203.

[33] Takagi T, Sugeno M. Fuzzy identification of systems and its applications to modeling and control. IEEE transactions on systems, man, and cybernetics. 1985:116-32.

[34] Jang J-SR, Sun C-T, Mizutani E. Neuro-fuzzy and soft computing; A computational approach to learning and machine intelligence. 1997.

[35] Saleh AE, Moustafa MS, Abo-Al-Ez KM, Abdullah AA. A hybrid neuro-fuzzy power prediction system for wind energy generation. International Journal of Electrical Power \& Energy Systems. 2016;74:384-95.

[36] Montgomery DC. Design and analysis of experiments: John Wiley \& Sons; 2008.

[37] Wu CJ, Hamada MS. Experiments: planning, analysis, and optimization: John Wiley \& Sons; 2011.

[38] Holman J. Experimental methods for engineers; 2001.

[39] Ibrahim TK, Rahman M. Effects of isentropic efficiencies on the performance of combined cycle power plants. International Journal of Automotive \& Mechanical Engineering. 2015;12:2914-28.

[40] Kurt H, Recebli Z, Gedik E. Performance analysis of open cycle gas turbines. Int J Energy Res. 2009;33:285-94.

[41] Ibrahim TK, Rahman M. Optimum performance improvements of the combined cycle based on an intercooler-reheated gas turbine. Journal of Energy Resources Technology. 2015;137:061601. 